\title{
As histórias em quadrinhos para a formação de leitores ecléticos: algumas reflexões com base em depoimentos de universitários
}

Valéria Aparecida Bari

Professora da Faculdade Paulista de Educação e Comunicação (FAPEC). Mestra e doutoranda em Ciências da Comunicação pela ECA-USP. Secretária-geral do Núcleo de Pesquisas de Histórias em Quadrinhos da ECA-USP (NPHQ/ECA).

E-mail: valbari@attglobal.net

Waldomiro Vergueiro

Professor titular da USP. Professor de graduação e pós-graduação do CBD/ECA/USP. Coordenador do Núcleo de Pesquisas de Histórias em Quadrinhos da ECA-USP (NPHQ/ECA). E-mail: wdcsverg@usp.br

Sob a alegação, muitas vezes procedente, de falta de recursos materiais, os ambientes escolares e seus serviços de informação não atingem efetivamente suas tradicionais funções sociais, ao mesmo tempo que são exigidos por novas demandas, importantes e inevitáveis. A Pedagogia, que até então disputou inúmeras funções sociais de formação com a Comunicação, agora se vê em um contexto inovador de interdisciplinaridade, potencializado pelas mídias.

Como cenário deste momento de aproximação, assiste-se a uma crise internacional da leitura e da própria cidadania, em que grande parte das ações desenvolvidas pelas escolas em relação à mídia não passa de tarefas impostas por um programa ou política pública, sem vínculo ou compromisso ético com os envolvidos, tratados menos como sujeitos de sua própria história do que como receptores da cultura de elites intelectuais. 
1. ANDREOLLI, Fernando Henrique; ARAKI, Denis Pierre; BRAZ, Soraya Cristina Valto; CANESQUI, Jean Carlo Mogge; CARVALHO, Paula Moura; DESTÁCIO, Leandro; ENOMOTO, Erika Mayumi; FREDERICO, Aline; FUKUSHIRO, Luiz F. de Prince; GUERREIRO Natália Ribas; HO, Lisa; KATO, Fábio Yoshiaki KOMURA, Adriana; MA GALHÃES, Leopoldo Doray; MARQUES, Renata de Lima; MATSUSHITA, Vivian Miwa; NAPOLEÃO Thomaz A. Mayer; PEREIRA, Daniel E. Macedo QUINTILIANO, Francin Pino; SANTOS, Karine Almeida dos: STAMATIU, Samantha; THÉ, Tatiana: WEBER, Mariana Bittencourt.
Para entender e acolher os sujeitos das ações comunicacionais como protagonistas e não mais como objetos, a formulação de novas aproximações teóricas é muito mais importante e prioritária que a disponibilização de recursos materiais. Nesse sentido, os novos conceitos de informação, conhecimento, saber e cultura passam pela valorização da capacidade humana, da interação, da inclusão, do estabelecimento de relações sociais em que a promoção da leitura será suplantada pela sua apropriação, ressignificação e inserção em vivências cotidianas. Assim, parece chegado o momento de integrar a leitura à educação formal, informal, continuada, ao lazer e entretenimento, à melhoria da qualidade de vida, enfim, como ato criativo de promoção da auto-realização e da felicidade de indivíduos e coletividades.

Discutindo esta função social da leitura, sob a ótica da apropriação individual e coletiva da cultura letrada na infância e adolescência, este artigo apresenta pesquisa que elegeu as histórias em quadrinhos como objeto de observação, demonstrando seu protagonismo no letramento, desenvolvimento do gosto pela leitura e como fonte de informações do mundo letrado, contextualizadas que são nas vivências da infância. Para tal, as atitudes e formas de fazer da Educação adquirem novos significados, delineando fronteiras epistemológicas com a Comunicação e outras áreas, baseadas nas relações sociais e na valorização do ser humano, bem como na afetividade e na mediação participativa e interativa da cultura.

A metodologia adotada foi determinante para a qualificação e quantificação do grupo-teste: os alunos da disciplina optativa Editoração de Histórias em Quadrinhos, oferecida pelo Departamento de Jornalismo e Editoração (CJE) da Escola de Comunicações e Artes da Universidade de São Paulo (USP). O grupo constitui-se de alunos universitários regulares de várias unidades da USP, todos inscritos na disciplina de forma voluntária, com disposição para executar pesquisas e ter os créditos inseridos em seu histórico escolar. O universo de fontes documentais primárias foi composto de redações elaboradas pelos alunos da disciplina citada, com o tema Minha Vida em Quadrinhos. Da amostra de 120 documentos pesquisados, elencamos aqui os depoimentos literalmente citados ${ }^{1}$. As características de diversificação não computadas foram: gênero, idade, área de estudo (alunos oriundos das ciências exatas, biológicas e humanas), motivações pessoais e perfil socioeconômico.

Como forma de sondagem, no primeiro dia de aula solicitou-se aos alunos a elaboração de um texto, de aproximadamente duas laudas, com o tema escolhido e para o qual foram orientados a rememorar e expressar suas experiências. As redações, depois de coletadas entre os anos letivos de $2001 \mathrm{e}$ 2004, lidas tecnicamente e indexadas em suas características mais interessantes para o desenvolvimento desta pesquisa, foram quantificadas e qualificadas para posterior estudo. Nesse sentido, a análise das redações gerou um perfil inicial no tocante ao relacionamento anterior do aluno com as histórias em quadrinhos; no entanto, embora exploratória, por meio dela foi possível estabelecer várias relações entre as histórias de vida e o objeto da disciplina 
e da pesquisa. Por meio de aproximações, pôde-se coletar e organizar uma série de indexadores, que permitiram conhecer coletivamente e comentar este perfil.

\section{PRIMEIRO CONTATO COM AS HISTÓRIAS EM QUADRINHOS}

Não posso negar as minhas raízes nos quadrinhos (ARAKI, 2004).

Para a grande maioria dos alunos, as primeiras memórias são relativas à apropriação da leitura pelas histórias em quadrinhos. Outros, pela natureza de seus primeiros contatos, consideraram mais relevante a leitura após a alfabetização, no momento de socialização e escolarização primária. Ainda temos um grupo mais restrito, que iniciou a leitura de quadrinhos em um momento posterior, na vida adulta, desvinculado da descoberta e domínio da linguagem escrita e iconográfica.

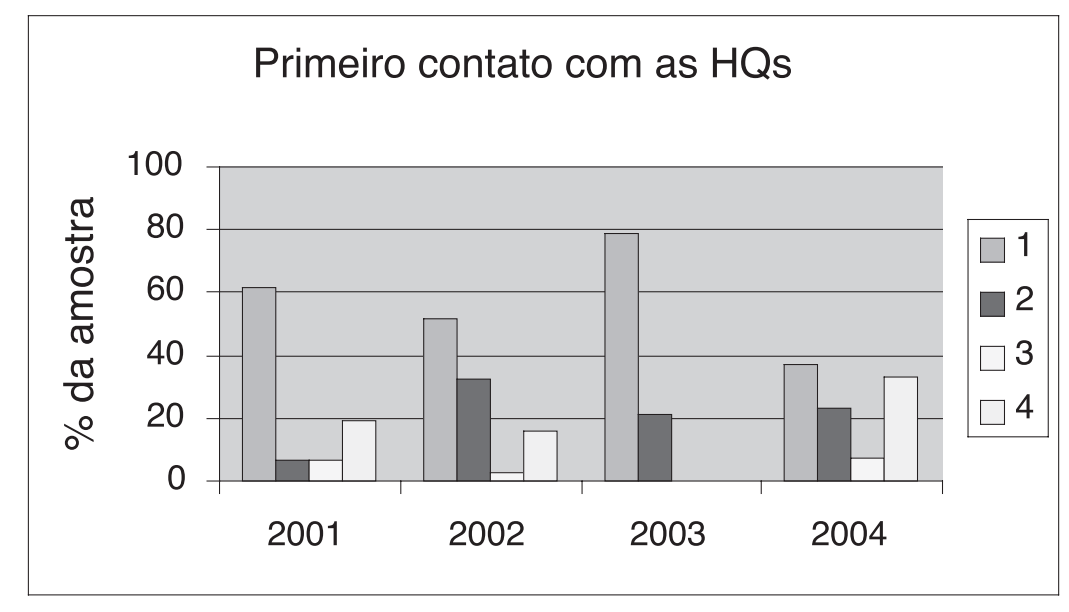

\footnotetext{
1 - Pré-alfabetizado

2 - Alfabetizado (em escolarização)

3 - Leitor pleno

4 - Não citado
}

Hegemonicamente, os depoimentos registrados nas redações apresentadas, com uma pequena diversificação na turma de 2004, dão conta de processos de alfabetização e socialização da cultura letrada motivados parcial ou totalmente pelas histórias em quadrinhos, como se pode constatar por meio dos depoimentos transcritos:

Esta paixão começou por volta dos cinco anos, idade na qual eu começara a aprender a ler. Todos os meus amigos compravam revistinhas e trocávamos entre nós as edições. Éramos fãs de Turma da Mônica e cada um de nós tinha um personagem favorito (SANTOS, 2004).

Minha relação com os quadrinhos iniciou-se assim que aprendi a ler. Aliás, foram os gibis que desenvolveram o meu prazer pela leitura (THÉ, 2004). 
Meu contato com histórias em quadrinhos é quase tão antigo quanto as primeiras lembranças que ainda estão na minha memória. Afinal, foi em grande parte com elas que aprendi a ler, aos três ou quatro anos, acendendo o estopim de um crescente interesse pela comunicação que, bem mais tarde, me levou ao curso de jornalismo (NAPOLEÃO, 2004).

As histórias em quadrinhos também atenderam às necessidades daqueles especialmente dotados para o letramento, desenvolvendo seu gosto pela leitura:

Aprender a ler aos quatro anos de idade acarreta um problema: o que ler? As páginas dos livros tão densas de letras, mesmo com figuras, não pareciam tão interessantes para uma criança. Surgiu então um gibi, mais precisamente um volume do Chico Bento. Não me lembro exatamente do sentimento daquele instante, mas deve ter sido bom, pois até hoje, quando posso, leio um gibi da Turma da Mônica - meio que escondido, as pessoas não compreendem (FUKUSHIRO, 2004).

Um dia, inexplicavelmente, folheando uma revista do Pato Donald, percebi que eu conseguia ler sem a ajuda de ninguém. Meus pais ficaram surpresos e pensaram que eu havia decorado a história, de tanto pedir que os outros a lessem para mim. [...] Foi dessa maneira que eu me tornei um leitor precoce (ANDREOLLI, 2002).

\section{GOSTO E CONTINUIDADE DA LEITURA DE HISTÓRIAS EM QUADRINHOS}

Quase a totalidade dos alunos manifestou ter lido continuamente histórias em quadrinhos durante a infância: alguns prosseguiram essas leituras de modo regular na adolescência, enquanto outros mudaram de interesses. Em geral, aqueles que desenvolveram o gosto pela leitura ou tiveram a sua continuidade na adolescência prosseguem com ela no período adulto, após a escolarização média. Existe, também, um grupo significativo de alunos que gosta de ler quadrinhos, mas o faz de forma esporádica ou descontínua.

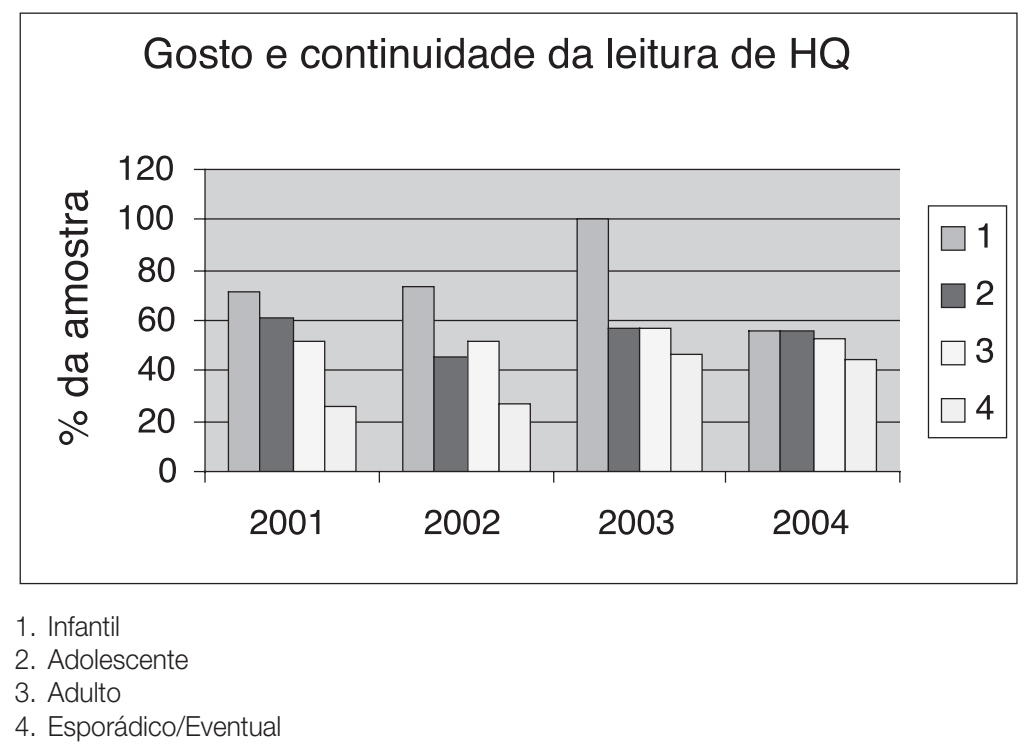


As primeiras lembranças da infância, narradas em um discurso repleto de adjetivos afetivos, denotam a emoção do contato com as primeiras letras no lar como um verdadeiro presente. Nesse sentido, o sentimento de pertencimento à comunidade e a integração progressiva no mundo da leitura ampliam a busca de novas experiências, que, na adolescência, costumam deteriorar a relação entre o leitor já proficiente e as histórias em quadrinhos ${ }^{2}$. No entanto, conforme constatado pela pesquisa, freqüentemente se dá uma reaproximação com a leitura de HQs na idade adulta, agora com critérios mais seletivos. É o que exemplifica o relato da aluna Natália Ribas Guerreiro:

Lembro-me, como se fosse hoje, da alegria que senti quando me contaram que eu tinha ganhado uma assinatura da Turma da Mônica. Exultava com a garantia de que teria aquelas páginas coloridas chegando, religiosamente. [...] Semanalmente eu recebia aquele pacotinho plástico cheio de Maurício de Sousa - e me sentia muito especial. Afinal, era a única e exclusiva correspondência que eu recebia e, como tinha a idade dos que ainda pensam que o mundo é só para eles, tinha a nítida impressão de que aquilo tudo tinha sido pensado e produzido só para mim. [...] Mas, como previsto, a temporada acabou e o fez quando outras leituras ocuparam seu lugar (sic). A partir daí, foi como se os quadrinhos tivessem ido para um lado e eu para outro. [...] Através de Garfield e Asterix, percebi que adulto também podia gostar dessas coisas - e foi muito bom (GUERREIRO, 2003).

Da mesma forma, em depoimentos recorrentes, como o da aluna Aline Frederico, a veemência atesta o protagonismo das histórias em quadrinhos tanto na apropriação da cultura letrada, quanto no desejo de militar pela multiplicação do universo de leitores:

No meu caso, os gibis foram fundamentais para o desenvolvimento do hábito de leitura. [...] Meu envolvimento com os quadrinhos hoje está relacionado principalmente à análise do mercado editorial e ao relacionamento com a criação do hábito de leitura em crianças e adolescentes, tema porque (sic) tenho profundo interesse (FREDERICO, 2003).

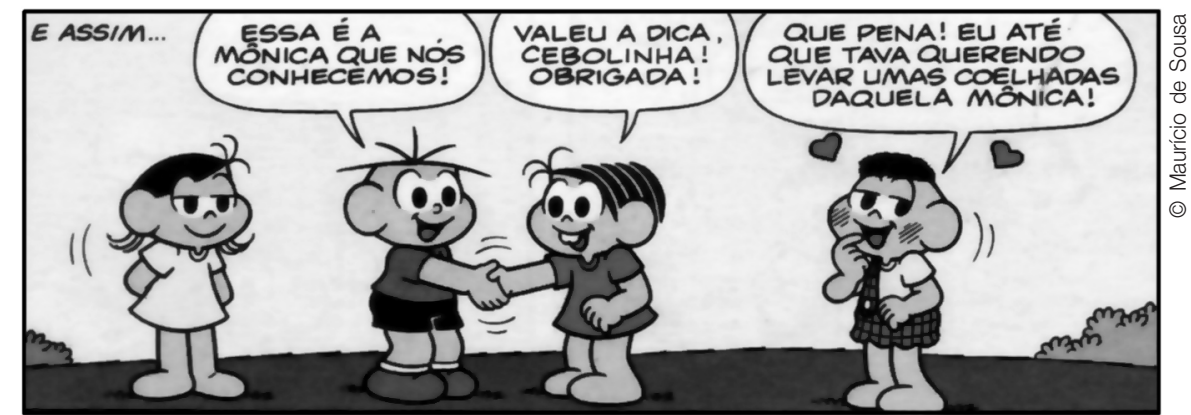

HQs: companheiras de crianças de todas as idades.

2. PUSTZ, Matthew J. Comic book culture: fanboys and true believers (Cultura de revistas em quadrinhos: fanáticos e verdadeiros crentes). Jackson: University Press of Mississipi, 1999. 
uma minoria que mantém ou desenvolve algum tipo de coleção, orientada por diferentes critérios, como série, personagem, autor, editora etc. Igualmente, uma parcela pequena, mas representativa, teve interesse em pesquisar obras relacionadas às histórias em quadrinhos ou seus processos de editoração, enquanto aproximadamente um quarto dos alunos já teve algum tipo de experiência com a produção de quadrinhos.

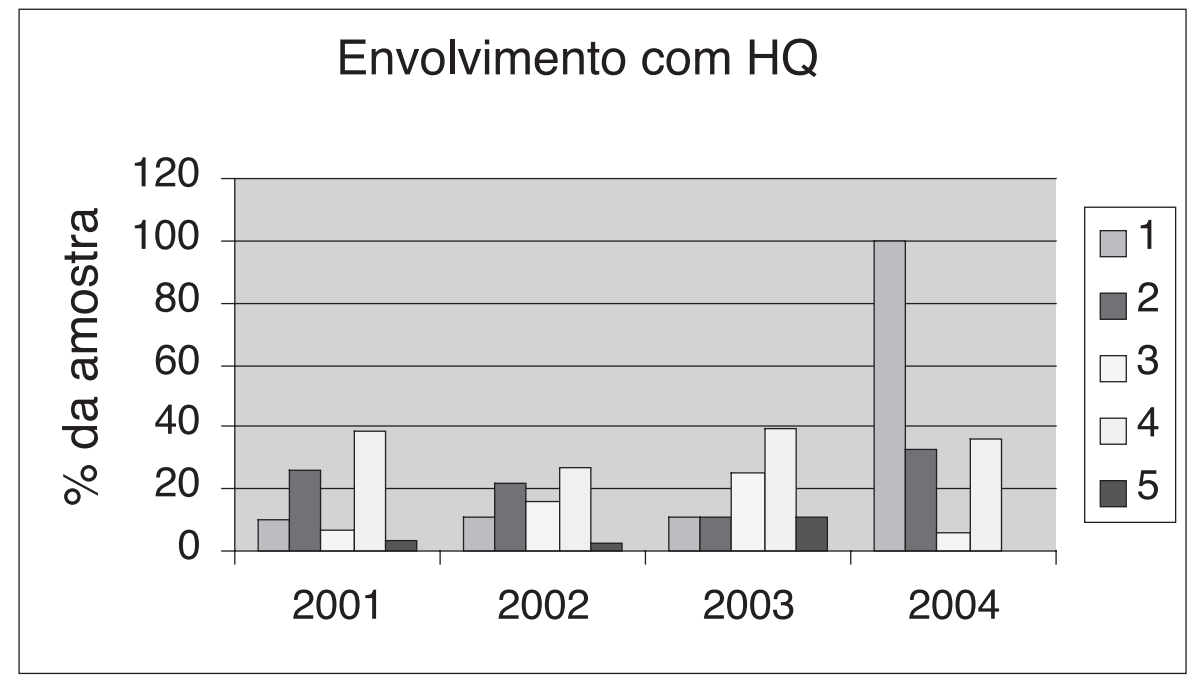

\footnotetext{
1. Gosto pela leitura de $H Q$

2. Manutenção/desenvolvimento de coleção de HQ

3. Pesquisa e leitura de obras relacionadas à $\mathrm{HQ}$

4. Produção de HQ

5. Aplicação de HQ em práticas pedagógicas
}

Em geral, é interessante notar que o gosto pela leitura de histórias em quadrinhos está vinculado, nos depoimentos, à sua presença em momentos alegres vividos pelo leitor, no seio da família ou nas bibliotecas escolares freqüentadas na infância:

Era uma grande alegria para mim e meus irmãos os dias nos quais meu pai chegava em casa com os exemplares de Chico Bento, Cascão, Cebolinha, Mônica etc. [...] Só parei de ler Maurício da Souza há uns três anos, quando meu pai faleceu. [...] Não me recordo o que me levou um dia a comprar um exemplar de Samurai X. [...] Comecei a colecionar [este e] outros títulos como Evangelion, Fushigi Yugui, Yuyu Hakusho. A leitura dessas histórias serve tanto como uma forma de me distrair e me desligar um pouco dos problemas da minha vida cotidiana, quanto como algo que me leva a fazer um exercício de reflexão sobre temas abordados nas histórias e que de alguma forma têm relação com minha própria vida (MATSUSHITA, 2003).

Já a preferência por produções estrangeiras parece se concentrar no mangá,

3. LUYTEN, Sonia Bibe. Mangá: o poder dos quadrinhos japoneses. São Paulo: Hedra, 2000. estilo desenvolvido no Japão, muito dinâmico e rico em gêneros e enredos ${ }^{3}$. Nesse sentido, a produção ocidental, polarizada em quadrinhos infantis e adultos, pode não mais contemplar o universo adolescente com a profundidade $\mathrm{e}$ procedência dos enredos orientais: 
Atualmente, leio mangá. Me encantam o roteiro e os traços japoneses de desenho, sobretudo aqueles relacionados com o cotidiano adolescente ou de heróis samurais (HO, 2001).

Por outro lado, no que diz respeito às histórias em quadrinhos nacionais, nota-se que a diversificação da produção gera um elenco eclético de preferências, desenvolvendo o gosto diferenciado na leitura de quadrinhos. É o que testemunha o aluno Daniel Pereira:

Com os quadrinhos brasileiros - principalmente com Lourenço Mutarelli - fui tomando contato com duas modalidades de quadrinhos que mais admiro atualmente, os alternativos e os autobiográficos (PEREIRA, 2001).

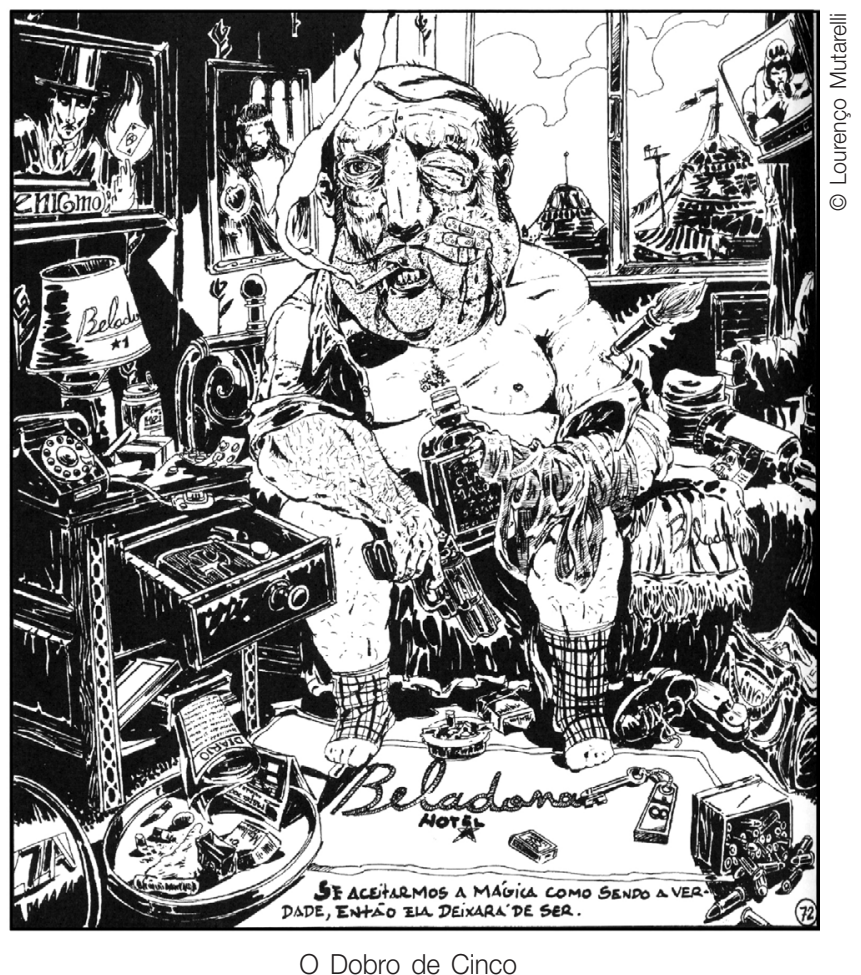

Em outros casos, a manutenção e desenvolvimento de coleções de revistas em quadrinhos colaboram na construção mental dos primeiros critérios ligados à organização, à preservação e à difusão do conhecimento, além de práticas saudáveis de higiene, organização pessoal e administração:

Depois de ler o gibi, guardava-o em uma grande caixa de papelão, onde estavam todos os outros. Dentro da caixa, as revistas eram separadas por personagem. A maior pilha era a do Cebolinha, o meu favorito (DESTÁCIO, 2003).

Já em relação ao estudo das histórias em quadrinhos, pode-se perceber que os depoimentos vão ao encontro do que defendem pesquisadores como Groensteen ${ }^{4}$, Vergueiro $^{5}$ e Witek ${ }^{6}$, entre outros, afirmando que este vem evoluindo, tomando corpo e seriedade no contexto mundial, devido, principalmente, à superação de uma visão limitada da Nona Arte e sua estreita vinculação ao discurso autori-

4. GROENSTEEN, Thierry. Why are comics still in search of cultural legitimization? (Por que os quadrinhos estão ainda em busca de sua legitimação cultural?). In: MAGNUSSEN, Anne; CHRISTIANSEN, Hans-Christian. Comics \& culture: analytical and theoretical approaches to comics (Quadrinhos e cultura: enfoques analíticos e teóricos aos quadrinhos). Copenhagen: Museum Tuscalanum Press, 2000. p. 29-41.

5. VERGUEIRO, Waldomiro. A pesquisa em quadrinhos no Brasil: a contribuição da universidade. In: LUYTEN, Sonia M. Bibe (Org.). Cultura japonesa. São Paulo: Hedra, 2005. p. $15-26$

6. WITEK, Joseph. Comics criticism in the United States: a brief historical survey (Crítica de quadrinhos nos Estados Unidos: um breve levantamento histórico). International Journal of Comic Art, v. 1, n. 1, p. 416, Spring/Summer 1999. 
tário e capitalista. Os universitários das diversas áreas têm buscado informações relevantes sobre a mídia e a linguagem das histórias em quadrinhos:

[...] só agora eu comecei a querer entender realmente a história, a personalidade dos personagens, as relações simbólicas etc. Isso porque, tendo sido sempre apaixonada por cinema, eu comecei a perceber como a linguagem cinematográfica e a dos quadrinhos são próximas. [...] ao invés de comprar quadrinhos, eu resolvi comprar dois livros que falavam sobre quadrinhos: Quadrinhos e Arte Seqüencial, do Will Eisner, e Understanding Comics, do Scott McLoud (KOMURA, 2003).

Nota-se, assim, que a pesquisa utilizando as histórias em quadrinhos como fonte primária incorpora-se progressivamente à esfera acadêmica, legitimando sua leitura não apenas como fruição estética e entretenimento, mas como prospecção de informações relevantes:

Em 2000, fiz um seminário usando a HQ Liga Extraordinária, na matéria História da Cultura, com o professor Nicolau Sevcenko. Nessa matéria analisei a HQ do ponto de vista das fontes literárias. [...] Hoje compro a linha Marvel da Panini [...], e venho cada vez mais percebendo que as HQs são um reflexo da nossa sociedade e portanto da nossa história, e por isso devem ser estudadas e usadas para aumentar o entendimento de "nós mesmos sobre nós mesmos" (MAGALHÃES, 2003).

Interesse pelo ser humano, histórias. Interesse pela linguagem escrita e visual. Hoje essas são as relações que me ligam aos quadrinhos e ao jornalismo, questões fundamentais das escolhas que venho fazendo na vida. [...] Graças a Deus pude ser brasileira a ponto de ler a Turma da Mônica e me identificar com a Mônica. [...] Acabei fazendo coleção da revista Herói [revista de divulgação e leitura crítica de HQs] e produzindo uma revista inspirada nela, a Herói Júnior. Isto aconteceu no Primeiro Colegial e o professor de geografia se interessou pela publicação. [...] Ele me presenteou com o livro História das Histórias em Quadrinhos de Álvaro de Moya (CARVALHO, 2003)

Provir de uma família letrada talvez ajude no desenvolvimento do gosto pela leitura de histórias em quadrinhos. Por sua vez, essa compreensão pode viabilizar a instrução técnica e a produção de histórias próprias. Muitas dessas iniciativas domésticas acabam por profissionalizar editores, desenhistas e roteiristas, renovando a produção brasileira, como enfatiza o seguinte depoimento:

A relação de leitora passou a mudar quando ganhei um livro sobre "como desenhar cartoons". Comecei a desenhar minhas histórias, uma maneira nova e deliciosa de dialogar com o mundo. Meus pais perceberam esta tendência e eu ganhei uma prancheta (mesa). Foi importante o apoio deles, sempre fui muito sensível à opinião dos outros (BRAZ, 2004).

Por outro lado, a desaprovação da família e da comunidade, assim como a visão depreciativa das histórias em quadrinhos, ainda que com a intenção de garantir o crescimento cultural, concorre para reprimir a individualidade e coibir a apropriação e a criação na esfera literária. No desabafo da aluna Francini Quintiliano, está expressa a mágoa pela imposição de uma visão preconceituosa da comunidade escolar, que inibiu sua individualidade e criatividade até a idade adulta e o ingresso na universidade: 
Somente agora tomo conhecimento de que não sou a única. Só agora tenho coragem de dizer do que gosto e o que quero para minha vida. [...] Agora sou capaz de me ver numa história em quadrinhos. Onde sou uma daquelas personagens que brigam para alcançar um objetivo (QUINTILIANO, 2003).

No entanto, os alunos também constataram que, tanto na Pedagogia como na Comunicação, ampliou-se o reconhecimento do valor da leitura das histórias em quadrinhos, que se vem constituindo em fontes de informação e conhecimento, progressivamente inseridas em práticas pedagógicas no ensino básico e fundamental:

Eu folheava gibis antes mesmo de aprender a ler. [...] Minha mãe (coordenadora pedagógica em um colégio estadual) diz que a leitura de quadrinhos na infância faz a diferença entre os bons e os maus leitores (MARQUES, 2004).

Evidentemente, meu primeiro contato foi com os quadrinhos de Maurício de Souza (sic). Apesar de hoje não concordar com alguns métodos utilizados pelos estúdios

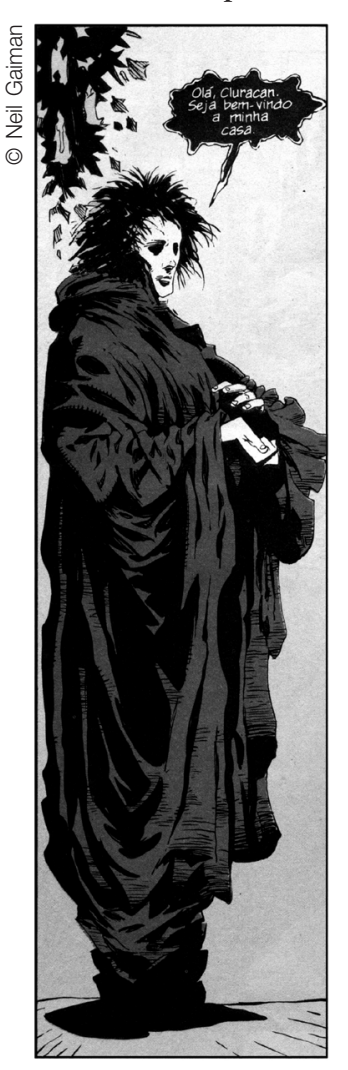

Sandman e outros quadrinhos adultos unem arte e literatura. dele, acredito que o seu trabalho deve ser amplamente respeitado e admirado, principalmente pelo fato de sua aplicação na educação e a já referida alfabetização de nossas crianças. [...] Hoje tento passar essa pequena experiência com os quadrinhos para os alunos de uma escola técnica estadual, em um curso básico de quadrinhos. Estou percebendo o quanto é prazeroso ensinar e não quero abrir mão disso por um bom tempo (PEREIRA, 2001).

Acredito em compromisso. Não acho que sou um agraciado por estar na USP. Penso que na verdade contraí uma dívida social e moral com as pessoas que pagam a Universidade e que tenho de retornar seu esforço. Quero fazer isso através da arte, literatura e quadrinhos (CANESQUI, 2001).

$\mathrm{Na}$ faculdade, tive uma disciplina na qual estudei Shakespeare e fiz um trabalho final relacionando, adivinhem, a obra e a adaptação em Sandman! Estou em meu último ano do curso de Letras, Inglês, e também da licenciatura, onde desenvolverei um curso de língua inglesa de doze aulas, utilizando histórias em quadrinhos. [...] meu objetivo é trabalhar na rede pública como professora e fazer com que as bibliotecas não sejam o único local com meia dúzia de gibis para a hora do intervalo (STAMATIU, 2004).

Essa ampliação de reconhecimento do valor da leitura de histórias em quadrinhos em ambientes escolares sinaliza para as novas funções sociais das bibliotecas escolares ${ }^{7}$, incorporando mídias e processos de mediação até agora insuficientemente valorizados.

\section{LEITURA DE QUADRINHOS NO UNIVERSO ESCOLAR}

Me lembro até hoje a rata de biblioteca que eu era, às vezes passando o recreio todo lendo livros e revistas em quadrinhos do acervo da escola. Não diferenciava uns dos outros em meu gosto. [...] Como era gostoso ler uma história novinha, descobrir suas surpresas e mostrar as partes mais divertidas para os meus pais (WEBER, 2002).

7. RAMA, Ângela; VERGUEIRO, Waldomiro (Orgs.) Como usar as histórias em quadrinhos na sala de aula. São Paulo: Contexto, 2004. (Como usar na sala de aula). 
As escolas - e, conseqüentemente, suas bibliotecas -, apesar da antiguidade de suas origens, ainda atuam em situações limítrofes, em terrenos sociais inóspitos, com falta de status e de recursos humanos e materiais. Desfalcadas de políticas internas visando à construção de relações em que os sujeitos atuem na fruição e na produção do conhecimento, assim como devido à deficiência na formação, que atinge tanto educadores como alunos, elas freqüentemente não alcançam o objetivo das práticas de leitura pública interativa ${ }^{8}$.

As histórias em quadrinhos podem contribuir para a reconfiguração dos ambientes escolares, estabelecendo relações diferenciadas com o estudante e ampliando o impacto social dessas instituições sociais. Isso pode ser constatado nos diversos depoimentos coletados nesta pesquisa, muitos deles demonstrando a efetividade da leitura de histórias em quadrinhos na formação de um leitor crítico, ativo, em condições de se apropriar e dialogar em alto nível com a cultura escrita. Nesse sentido, é essencial que os responsáveis pelas políticas públicas educacionais estejam abertos ao potencial benefício das histórias em quadrinhos para a educação.

\section{CONSIDERAÇÕES FINAIS}

Talvez os quadrinhos reúnam tudo o que há de melhor no cinema, na literatura e na pintura. Ou talvez seja "só" o que é: simplesmente quadrinhos (KATO, 2004).

Estudos sobre o impacto da leitura de histórias em quadrinhos na formação de leitores ainda são esparsos e pouco sistematizados. Este artigo, exatamente por representar uma aproximação inédita ao tema em ambiente universitário brasileiro, constitui apenas a abertura de novos espaços para investigação da área. Espera-se, dessa forma, que os profissionais de Educação e Comunicação sejam sensíveis às constatações iniciais aqui apresentadas, ampliando seu escopo e aplicação.

8. RIBEIRO, Vera Masagão (Org.). Letramento no Brasil. São Paulo: Global, 2003.
Resumo: A partir de depoimentos de universitários, discute-se a relação entre a leitura de histórias em quadrinhos e o gosto pela leitura - constatando-se que este se iniciou no contato com as publicações da Nona Arte, antes mesmo do período de alfabetização -, bem como o afastamento posterior das histórias em quadrinhos em benefício de outras leituras, mais utilitárias (livros e manuais de estudo). Os autores concluem pela defesa da inclusão de materiais quadrinhísticos no ambiente escolar em geral, aconselhando a familiarização dos profissionais de educação e informação com a mídia e a linguagem dos quadrinhos.

Palavras-chave: história em quadrinhos, leitura, leitura escolar, gosto pela leitura.
Abstract: From university students' statements, the article discusses the relationship between Comics reading and the joy of reading, identifying the occurrence of this joy in the first contacts with the publications of the 9th. Art, even before the first years of school, as well as those students get away from comics lately and looked for other kinds of readings, considered more useful to them (books and students manuals). The authors conclude defending the inclusion of comics' materials in the schools, advising education and information professionals to become acquainted with the media and the comics' language.

Keywords: comics, reading, school reading, joy of reading. 